\title{
OS ATUAIS DESAFIOS DA PESQUISA E DA EXTENSÃO UNIVERSITÁRIA E A CONSTRUÇÃO DE ESTRATÉGIAS COLETIVAS DE TRABALHO: experiências na área da saúde*
}

\author{
Carlos Antonio de Soura Moraes \\ Eliana Monteiro Feres \\ Maria da Penha Lyrio Barreto Moura
}

\section{Introdução}

O tempo presente é marcado pela precarização da vida e do trabalho, associado ao avanço do conservadorismo, ao ataque à institucionalidade trabalhista, à manipulação de informações e à ascensão da pós-verdade ${ }^{1}$ que distorcem fatos e dados e que se sustentam por meio de investidas contrárias à ciência, recorrendo ao negacionismo científico como estratégia política de manutenção do projeto neoliberal, em sua versão mais radical.

Originado nos Estados Unidos, na década de 1950, o negacionismo científico foi elaborado pela indústria de tabaco, que objetivava convencer a população de que as evidências de doenças associadas ao uso do tabaco eram falsas, recorrendo a propagandas pagas a jornais impressos para atingir a população americana. Além disso, evocaram supostos especialistas que descreditavam tais consensos científicos, construindo dúvidas no imaginário popular, também fortalecidas pela disseminação de tais argumentos pela mídia (PIVARO; JUNIOR, 2020).

Com o passar dos anos, houve o fortalecimento dos resultados científicos acerca das doenças geradas pelo uso do tabaco. Contudo as estratégias construídas, centradas no mercado e com o objetivo de moldar a opinião pública e criar confusão popular, desenvolveram-se.

Nos últimos anos, o negacionismo científico tem-se disseminado via internet, com destaque para as redes sociais que, diferentemente do passado, atingem velozmente milhões de sujeitos e em diferentes regiões do globo. Além disso, também tem investido em programas televisivos partidários e, no contexto americano, articulado a doações milionárias realizadas por companhias de petróleo, gás natural e mineração, para membros do congresso que recorrem à grande mídia para propagar seus discursos, popularizando dúvidas sobre consensos científicos (PIVARO; JUNIOR, 2020).

Ao particularizar a realidade brasileira, verifica-se seu alinhamento aos interesses norteamericanos, centrados no mercado e no lucro acima da vida. Parte da impressa internacional reconhece o presidente Jair Bolsonaro (2018-2022) como "Trump tropical”, em alusão ao expresidente dos Estados Unidos Donald Trump (2017-2021). A título de exemplo, Pivaro e Júnior (2020) ressaltam que preocupações sobre o aquecimento global, por vezes, são tratadas, no Brasil, como "alarmismo", e muitas dessas posições são propagadas pelas redes sociais, acompanhadas pela proliferação de fake news.

\footnotetext{
${ }^{*}$ DOI- 10.29388/978-65-81417-27-7-0-f.190-202

${ }^{1}$ Segundo Pivaro e Júnior (2020, p. 1.083), a pós-verdade é definida como “[...] circunstâncias em que fatos objetivos são menos influentes na formação da opinião pública do que emoções e crenças pessoais (OXFORD DICTIONARY, 2016)", havendo uma "[...] ampliação da subjetividade da realidade para diversos aspectos, além da negação da ciência".
} 
Assim, observa-se um processo de subversão de dados científicos, tornando-os objeto de julgamento pessoal, de forma que se possa encaixar a realidade a suas opiniões (PIVARO; JUNIOR, 2020). Além disso, já nos primeiros meses do governo Bolsonaro, foram publicizadas críticas pelo presidente e pelo então ministro da Educação, Abraham Weintraub (2019-2020), ao patrono da educação brasileira Paulo Freire, a professores, à pesquisa, às universidades públicas e à ciência brasileira, especialmente à área de humanidades. Além dessas, em 2019, foi criada a proposta do Programa universidades e institutos empreendedores e inovadores (Future-se) ${ }^{2}$, além de terem sido promovidos cortes no orçamento da Educação e da Ciência e Tecnologia, sucateando o ensino superior público, congelando pesquisas, reduzindo bolsas de estudos e ameaçando a continuidade de serviços e laboratórios.

Além desses ataques, a universidade brasileira tem-se inspirado, cada vez mais, na concepção estadunidense de ensino superior, a partir de seu conteúdo pragmático e utilitário e, além disso, recorre ao princípio de racionalização, embasado em concepções tecnicistas e empresariais de produtividade, eficiência e eficácia (TAUCHEN; FÁVERO, 2011).

Contraditoriamente, o contexto de precariedade e de ataques ao ensino superior público, no Brasil, também tem sido marcado por melhora significativa no principal ranking do Times Higher Education (THE) e, além disso, o Brasil alcançou, no mundo, índices no top 1\% em relação a citações de trabalhos e atingiu a $13 .{ }^{a}$ posição na produção científica global, considerando todas as áreas de conhecimento (SHUTZ; FUCHS; COSTA, 2020).

O fato é que, mesmo nessas condições estruturais e conjunturais, a pesquisa científica resiste, ao centrar-se no coletivo, desafiando a refletir e a questionar a realidade social sob diferentes perspectivas. Nesse mundo marcado pela competitividade, pelo individualismo e pela apropriação superficial de conhecimentos, o pensamento e a prática social coletiva são estratégias importantes, e a universidade é um dos poucos espaços que ainda os valoriza. Para tanto, a universidade desafia-se a contextualizar os rumos do desenvolvimento científico e tecnológico e a indagar-se sobre eles, reconhecendo suas condições sócio-históricas, evitando compreensões redutoras da realidade e se colocando como espaço livre, democrático, reflexivo e crítico (SHUTZ; FUCHS; COSTA, 2020).

Assim, a pesquisa assume o papel de desocultar as contradições presentes na realidade social, por meio da construção permanente da consciência crítica e política, alicerçada na responsabilidade, na ética e no compromisso com um mundo justo e livre.

Para estreitar e fortalecer essa relação, a universidade desenvolve a extensão, reconhecendo o seu papel frente aos problemas sociais. De acordo com o Plano Nacional de Extensão (BRASIL, 2012), ela se insere como uma prática acadêmica que objetiva interligar a universidade às atividades de ensino e pesquisa a partir de demandas da sociedade.

Portanto, como articulação entre ensino e pesquisa, a extensão possibilita a construção de diálogos entre universidade e sociedade, a partir de interesses e de necessidades da população, caracterizados pela troca de saberes e a superação de um discurso de hegemonia acadêmica, no sentido de enfrentar a desigualdade social, privilegiando o caráter interinstitucional e interdisciplinar, além de sua indissociabilidade com a pesquisa e com o ensino (PRATES, 2017).

\footnotetext{
2 Nenhuma proposta de projeto de lei de reforma das instituições de educação superior federais, no Brasil, nas últimas décadas, desde a promulgação da Constituição Federal de 1988, reuniu tantos preceitos econômicos e políticos (ultra)neoliberais como a denominada Future-se. Ancorado em tais características, por iniciativa do Ministério da Educação, o Future-se tornou reais os piores temores da maioria dos membros da comunidade universitária das universidades e institutos federais quanto a seu presente e a seu futuro: decorrentes da Emenda Constitucional n. 95, de 15 de dezembro de 2016 (GIOLO, 2020).
} 
Nesse sentido, reconhecemos que, por meio da extensão, é possível ofertar serviços à sociedade, desenvolver trabalhos político-pedagógicos, redimensionar processos de ensinoaprendizagem e construir propostas metodológicas de pesquisa que ultrapassem técnicas pontuais de investigação, por meio de aproximações críticas com o universo de trabalho e estudo.

Sintonizado com essa perspectiva, o Grupo Interdisciplinar de Estudo e Pesquisa em Cotidiano e Saúde (Gripes) desenvolveu, no período de 2016 a 2019, um projeto de pesquisa e extensão intitulado Entre o "adoecimento social" e a hegemonia do Modelo Biomédico Assistencial: o trabalho de assistentes sociais na área da saúde. Esse projeto foi planejado e inicialmente se desenvolveu em parceria com a coordenação do Serviço Social de um hospital no Norte Fluminense, por meio de encontros mensais no auditório da instituição e direcionado ao conjunto de assistentes sociais e de estagiárias atuantes no hospital, com o objetivo de fortalecer a identidade da profissão na área da saúde, por meio da potencialização da capacidade crítico-analítica da assistente social, articulada a ações propositivas.

Posteriormente essa proposta foi articulada ao Conselho Regional de Serviço Social (Cress), 7. ${ }^{a}$ Região, Seccional Norte Fluminense, e à Coordenação do Serviço Social de outro hospital de referência na região, sendo realizada mensalmente, no auditório da instituição e direcionada a assistentes sociais e a estagiárias daquele hospital, da cidade e de municípios vizinhos. Por fim, foi organizado um curso para assistentes sociais e para estagiárias da Fundação Municipal de Saúde de Campos dos Goytacazes, RJ.

Diante disso, neste capítulo, serão apresentados dados e análises referentes a essas experiências, destacando a relevância de um trabalho coletivo que, pautado em fundamentos teórico-metodológicos, ético-políticos e técnico-operativos, reconhece a realidade como ponto de partida, analisando suas contradições, limites e possibilidades. Assim, recorreremos aos processos de construção da proposta, às articulações políticas, à participação discente e das assistentes sociais, aos resultados alcançados e às avaliações realizadas, dividindo o capítulo em três seções, além de sua introdução e conclusão. Na primeira, serão descritos os movimentos construídos pelo Grupo de Pesquisa. Posteriormente, as análises desenvolvidas pela coordenação do Serviço Social do Hospital e, por fim, pela então diretora do Cress, Seccional Norte Fluminense.

\section{Articulações de propostas coletivas de pesquisa e extensão: registros do Gripes}

Como vimos, as atuais transformações processadas no cenário mundial, em uma era de radicalismo neoliberal, impactam em todos os âmbitos da vida social, dando um novo conteúdo à vida e ao trabalho, e se articulam ao avanço do conservadorismo, ao ataque a direitos trabalhistas e à ascensão da pós-verdade, que recorre ao negacionismo científico como estratégia política de manutenção do projeto neoliberal.

Nesse cenário de desfinanciamento das políticas sociais, de sucateamento da universidade pública e de cortes de seu orçamento, tem sido urgente a construção de estratégias coletivas que objetivem o desocultamento das contradições da sociedade do capital e a mobilização de recursos para o seu enfrentamento. Nessa direção, foi construída uma proposta de pesquisa e de extensão a partir de demandas apresentadas ao Gripes, pela Coordenação do Serviço Social de 
um Hospital localizado no Norte Fluminense. Para este projeto, reconheceu-se o fazer profissional do Serviço Social a partir da categoria trabalho e objetivou-se fortalecer a capacidade crítico-analítica das assistentes sociais, articulada a ações propositivas pautadas em sistematização e planejamento do trabalho profissional, na direção da qualidade dos serviços prestados à população, conforme estabelecido no $100^{\circ}$ princípio do Código de Ética profissional (CFESS, 1993).

No eixo da extensão, a proposta objetivou contribuir para a qualificação continuada das assistentes sociais, a partir de identificação, de discussão e de análise permanente dos dilemas, dos desafios e das possibilidades vinculados ao trabalho na área da saúde, tendo, por base, as mudanças do capitalismo contemporâneo e suas implicações para a "questão social" e, consequentemente, as necessidades sociais em saúde.

As atividades de extensão foram sistematicamente planejadas pela equipe organizadora, que contou com a participação de um professor gestor e coordenador do projeto, de uma assistente social, de duas graduandas em Serviço Social pela Universidade Federal Fluminense, Departamento de Serviço Social de Campos, e de uma assistente social doutoranda em Política Social, pela Universidade Estadual do Norte Fluminense, além das contribuições da coordenadora do Serviço Social do hospital mencionado.

O planejamento dos seminários de qualificação ocorreu na sala do Gripes e foi desenvolvido pelo núcleo de estudos Serviço Social e Saúde, sob coordenação do Professor Gestor do Projeto. As atividades de planejamento comportaram análises de textos, debates em grupos e organização do material dos seminários de qualificação.

No eixo da pesquisa, a proposta pautou-se na dimensão bibliográfica e de campo. A pesquisa de campo ocorreu por meio da disponibilização de questionário às assistentes sociais participantes do projeto a fim de identificar, de forma mais aprofundada, dilemas, desafios e possibilidades do trabalho profissional, na área da saúde, avaliando as contribuições do curso de extensão para ampliação de conhecimentos e de suas implicações para a reconstrução das estratégias de ação.

Articulado ao trabalho de campo, realizamos estudos bibliográficos a respeito do tema Serviço Social e trabalho profissional na área da saúde. Esses estudos estiveram vinculados a produções dos primeiros anos do século XXI publicadas em livros e nos principais periódicos da área.

Nesses processos, objetivou-se problematizar o trabalho profissional da assistente social na área da saúde, especialmente nos espaços hospitalares, analisando seus determinantes objetivos. Partiu-se da hipótese de ameaça à dimensão intelectiva do trabalho na perspectiva do projeto ético-político profissional, conforme apontado por Moraes (2016).

Os cursos de qualificação foram desenvolvidos por meio de seminários mensais, com duração de quatro horas, comportando apresentações dos temas programados, debates a seu respeito e indicação de atividades de sistematização do trabalho e de seu estudo para os demais encontros. Além disso, foram realizados, na sala de estudos e de reuniões do hospital, intercalados entre segundas e terças-feiras, com o objetivo de contribuir para que as profissionais que tivessem maior dificuldade em um dia, participassem, no mês seguinte, do seminário, por ser em dia alternativo.

Todo o trabalho de qualificação foi observado e sistematizado por uma aluna de graduação, estagiária do hospital e integrante do Gripes. Essa sistematização, além de permitir a avaliação da ação de extensão proposta, contribuiu para construção de novas análises pautadas 
nas variáveis despontadas durante a capacitação e naquelas identificadas como relevantes em outra pesquisa (MORAES, 2016).

Ao longo dos encontros, foi possível identificar, entre relatos profissionais, a precariedade da política de saúde pública e dos serviços/instituições que não dispõem de recursos para o atendimento das demandas originadas pela contradição da acumulação capitalista, destacando a necessidade de conhecer, de maneira aprofundada, o financiamento da política de saúde, bem como chamaram a atenção para a importância de se colocar no lugar dos usuários que, por diversas vezes, não têm suas demandas ouvidas e, por conseguinte, seus direitos não são garantidos.

Ademais, os relatos das assistentes sociais sinalizaram para dificuldades profissionais na realização do trabalho no hospital, de maneira geral; dificuldades por setor de atuação; dilemas; e desafios profissionais. Mediante a sistematização dos relatos publicizados ao longo dos encontros, o grupo de pesquisadores, a gestora do Serviço Social do hospital e o grupo de assistentes sociais discutiram e construíram 12 itens relativos a possíveis encaminhamentos para o trabalho, na realidade hospitalar, reconhecendo seus determinantes objetivos e os limites do trabalho.

Essa experiência, seus resultados e análises foram sistematizados em um relatório técnico, apresentado e disponibilizado ao grupo de assistentes sociais do hospital após a finalização do curso. Além disso, foram socializados com a comunidade científica em eventos nacionais e por meio de publicações em seus anais ${ }^{3}$ e periódicos ${ }^{4}$.

Os resultados dessa experiência possibilitaram que novas ações fossem articuladas com a coordenação do Serviço Social de outro hospital de referência na região. Concomitantemente, foi estabelecida parceria com o Conselho Regional de Serviço Social (Cress), Seccional Norte Fluminense, que ampliou a divulgação do projeto e possibilitou que ele atendesse, além das profissionais do referido hospital, assistentes sociais de Campos dos Goytacazes, de Macaé e de Bom Jesus do Itabapoana.

No total, ambas as iniciativas alcançaram, aproximadamente, um quantitativo de 40 assistentes sociais, o que também possibilitou novas articulações com as coordenações do Serviço Social dessas instituições, por meio da realização de eventos, bem como com o Cress, Seccional Norte Fluminense, especialmente por meio da realização do Curso de qualificação para assistentes sociais da Secretaria Municipal da Saúde e de Programas Especiais de Saúde do município de Campos dos Goytacazes - RJ, realizado também em parceria com a Coordenação do Serviço Social da Secretaria Municipal de Saúde, ao longo do mês de novembro de 2019.

Por fim, é possível afirmar que tais iniciativas estreitaram os diálogos entre universidade, entidade representativa da categoria e assistentes sociais/supervisores de estágio, sob perspectiva multidimensional; 1. Fortalecendo as estratégias coletivas de pesquisa e extensão; 2. Promovendo, entre as discentes integrantes do projeto, exercícios de planejamento, de participação em grupo de estudos, de sistematização e de avaliação do trabalho, sob supervisão e orientação docente; 3. Aprofundando a pesquisa a respeito do trabalho da assistente social na

\footnotetext{
3 MORAES, Carlos Antonio de Souza; CORDEIRO, A. P. P ; BOTELHO, T. M. ; ARAÚJO, M. M. ; SILVA, L. A. da . Entre o 'adoecimento social' e a hegemonia do modelo biomédico assistencial: o trabalho dos assistentes sociais em hospitais. In: Congresso Nacional de Serviço Social em Saúde, 2017, Campinas. VIII Congresso Nacional de Serviço Social em Saúde e XI Simpósio de Serviço Social em Saúde, 2017.

4 MORAES, Carlos Antonio de Souza; BOTELHO, T. M. ; SILVA, L. A. da ; ARAÚJO, M. M. ; CORDEIRO, A. P. P . Serviço Social e trabalho profissional em hospital. VÉRTICES, v. 20, p. 372-384, 2018.
} 
área da saúde, especialmente em espaços hospitalares, superando técnicas pontuais de coleta de dados; 4. Articulando com o ensino, por meio do debate do trabalho profissional; e 5. Desenvolvendo ações de qualificação profissional, construídas sob o parâmetro da crítica, contribuindo para suspenção temporária de seu cotidiano de trabalho, oxigenando as percepções que têm da instituição, das demandas, das possibilidades e dos limites do trabalho.

\section{Articulações de propostas coletivas de pesquisa e extensão: registros da coordenação do Serviço Social de um hospital de referência no Norte Fluminense}

Atuando no Serviço Social na área de Saúde, no município de Campos dos Goytacazes, em unidade pré-hospitalar, a partir de 2003, iniciamos o processo de trabalho e de reflexão sobre a atuação do Serviço Social na implantação dos plantões nas respectivas unidades hospitalares e a participação efetiva no grupo de Assistentes Sociais da Fundação Barcelos Martins (hoje Fundação Municipal de Saúde). Período de grande importância em que definimos protocolos, após discussões teórico-práticas, parcerias com professores da Universidade Federal Fluminense, iniciamos o processo de sistematização do trabalho profissional, de implantação do estágio supervisionado e de realização de pesquisa sobre o usuário e sobre o acesso a serviços e direitos. Foram anos de grandes avanços e lutas.

Em 2013, assumindo a Coordenação do Serviço Social de uma hospital de referência no Norte Fluminense, unidade de emergência que atende o município de Campos dos Goytacazes e a Região Norte Fluminense, um novo desafio surge a partir do conhecimento sobre a realidade, trabalho da equipe, trocas, escutas, aproximações sucessivas e planejamento das ações junto da equipe de assistentes sociais, identificando a necessidade de avançar na direção da qualificação profissional, na sistematização do trabalho, na reabertura de campo de estágio (proposta da Coordenação) e na articulação com a Universidade, que se foi ampliando gradativamente, até a extensão, em 2016. Diríamos que a "espinha dorsal" estava direcionada para o fortalecimento da categoria profissional, para o comprometimento com o Projeto Ético-Político do Serviço Social e para o debate contemporâneo da profissão, eixos esses de fundamental importância no planejamento das ações da coordenação, em meio a grandes desafios, conquistas, avanços e recuos. Como dizia o poeta Thiago de Melo (2018): "Quem sabe o que está buscando e onde quer chegar, encontra o caminho certo e o jeito de caminhar".

Em novembro de 2013, com quatro meses de coordenação, convidamos o assistente social professor doutor Maurílio de Castro Matos, que nos trouxe reflexões fundamentais para o âmbito de atuação na saúde e, especificamente em unidade hospitalar, por meio do Encontro de Assistentes Sociais da Saúde promovido pela Coordenação do Serviço Social do referido Hospital. O referido encontro trouxe reflexões a respeito do processo de sistematização do trabalho profissional e também dos parâmetros do Serviço Social na área da saúde. Diríamos que foi um grande pontapé inicial para pensar as atividades na unidade hospitalar, contando com a participação de Assistentes Sociais da Saúde, compreendendo unidades hospitalares e préhospitalares.

Posteriormente, a articulação com a extensão universitária, especialmente por meio do Curso de Serviço Social da UFF/Campos, se tornou uma proposta na direção de ampliar conhecimentos sobre a realidade social $\mathrm{e}$ as possibilidades de construir intervenções 
fundamentadas na crítica, no comprometimento com os usuários e com o acesso a direitos sociais, exercitando o pensar na direção da sistematização do referido trabalho, enquanto

[...] estratégia para um exercício profissional qualificado, uma vez que pode ser uma aproximação com a realidade, mas há que se ter claro que isso é distinto da simples junção de dados coletados pela equipe de Serviço Social, pois estes tomados na sua aparência, sem uma problematização teórica e ou desenvolvimento de pesquisas, serão a fenomênica da realidade (MATOS, 2013, p. 138, 139).

A coordenação seguiu, ao longo da gestão, discutindo e implementando os protocolos de intervenção do Serviço Social, movimento que aconteceu na unidade, com todos os setores, devido às suas especificidades, com base inclusive nos Parâmetros para Atuação do Serviço Social na Saúde (CFESS, 2009).

Buscando a direção teórico-prática, seguimos em articulação com o assistente social, professor Dr. Carlos Antonio de Souza Moraes, e o foco foi sugerir uma proposta alinhada com a extensão universitária, por meio do Grupo Interdisciplinar de Estudo e Pesquisa em Cotidiano e Saúde (Gripes), nascendo a parceria da Coordenação do Serviço Social de um Hospital de referência no Norte Fluminense com o Gripes. Discutimos as demandas profissionais, trocamos ideias, e foi possível construir a proposta Entre o "adoecimento social" e hegemonia do Modelo Biomédico Assistencial: o trabalho dos assistentes sociais na área da Saúde.

Sendo assim, iniciamos, em 2016, com encontros mensais, tendo, como participantes, a equipe do Serviço Social hospitalar, que atuava em seis clínicas, como: Cirúrgica; Traumato Ortopedia; Médica; Pediatria; Doenças Infecto-Parasitárias; Tisiologia; e também nas Unidades de Terapia Intensiva (UTI adulto e UTI pediátrica) e no Ponto Socorro. Afinados com a proposta de estágio supervisionado na unidade que foi reaberta por essa Coordenação, envolvemos também as estagiárias da UFF que estavam sob supervisão de assistentes sociais do Hospital.

Foram encontros profícuos que certamente contribuíram efetivamente para o conhecimento do Serviço Social e de sua trajetória na saúde, com reflexões sobre o trabalho profissional e possíveis estratégias de sustentação e de identificação de demandas sociais que representam o foco da atuação do Serviço Social em qualquer espaço de intervenção.

Assim, foi possível investir na discussão teórico-prática e na pesquisa se constitui num compromisso da categoria com o trabalho profissional que se deve se mostrar inquieta.

A trajetória continua não mais na Coordenação do Serviço Social da unidade, pois existe um tempo de investimento e outro de trilhar novos caminhos, novas perspectivas, não perdendo a direção, pois essa é mais importante que a velocidade. Atuando na mesma unidade hospitalar na área da infância, participando também de comissão junto à rede de serviços e de proteção na área, a partir de 2019, para discussão e implantação do Plano Municipal da Infância e Juventude, a inquietação deve-nos mover para novos horizontes, como ressalta Iamamoto (1995): é preciso retomar a práxis da resistência. "O momento em que vivemos é um momento pleno de desafios mais do que nunca é preciso ter coragem. É preciso ter esperanças para enfrentar o presente. É preciso resistir e sonhar".

Em meio a uma pandemia jamais vivida no mundo inteiro, nos últimos 100 anos, seguimos na direção dos nossos sonhos e comprometidos com o Serviço Social, profissão que 
escolhemos e acreditamos que faz grandes diferenças nos cenários de fortes marcas de desigualdade e de exclusão.

\section{Articulações de propostas coletivas de pesquisa e extensão: registros do Cress-RJ, Seccional Norte Fluminense}

Isolados somos ilha e juntos somos continentes. Essa frase representa bem a experiência realizada junto ao Gripes, Grupo de pesquisa e extensão da Universidade Federal Fluminense e a Seccional Norte Fluminense, na gestão 2017 a 2020, "Lutar sem temer", como estratégia coletiva de enfrentamento à desvalorização postas a universidade pública e a educação como direito social.

Quando assumimos a direção do Cress-RJ, Seccional Norte Fluminense (gestão 20172020), nossa proposta de gestão tinha, como um dos pilares, a parceria com a Universidade, com o objetivo de favorecer o aprimoramento profissional, considerando que a qualificação sempre esteve presente nas demandas das profissionais, e que a qualificação profissional sempre foi defesa do Conselho Federal de Serviço Social (Cfess) e dos Cress. O conjunto, na gestão 2014 a 2017, publicou a brochura Política de Educação Permanente do conjunto Cfess/Cress ${ }^{1}$, considerando que o aprimoramento profissional fortalece um dos princípios fundamentais do Código de Ética do/a Assistente Social (1993), no que se refere ao "compromisso com a qualidade dos serviços prestados à população", sobretudo no cenário de retrocesso no campo dos direitos sociais e os efeitos mais gerais da conjuntura política, sem os quais é impossível compreender as atuais demandas ao trabalho profissional.

Um dos maiores desafios postos à assistente social é o de atuar sobre a realidade e identificar, de forma crítica, as demandas postas pela população, respondendo, de forma eficiente, com vistas ao compromisso da categoria com a qualidade dos serviços prestados à população. Assim o Cfess/Cress (2012, p. 8) aponta que:

[...] pensar a educação permanente no Serviço Social pressupõe, portanto, afirmar o projeto profissional, articulando uma dupla dimensão: de um lado, as condições macrossocietárias que estabelecem o terreno sócio-histórico em que se exerce a profissão, seus limites e possibilidades; e, de outro, as respostas de caráter ético-político e técnico-operativo dos/as agentes profissionais.

Sobre os limites que vivenciam a profissão, destacamos que a crise estrutural do capital, na busca por recuperar as taxas de lucros, ocorre a partir do aprofundamento da desigualdade social, com a ampliação da distância entre ricos e pobres e principalmente com a reconfiguração do papel do Estado. No Brasil, a ofensiva neoliberal ocorre logo após a promulgação da Constituição Federal de 1988, em que o reconhecimento da Seguridade Social como direito do cidadão e como dever do Estado se depara com a proposta de diminuição do papel do Estado. E, a partir golpe, em 2015; da eleição da extrema direita, em 2017; e da aprovação da Emenda Constitucional n. 95/2016, com congelamento dos gastos com Saúde, Educação, Assistência Social, e Previdência Social por vinte anos, a classe trabalhadora vem pagando um alto preço com a precarização dos serviços que trabalham direitos sociais.

Paralelemente ao ajuste fiscal e à precarização dos serviços públicos, com foco na privatização, a eleição da extrema direita, em 2017, evidenciou o pensamento conservador 
presente na sociedade brasileira, e propostas de militarização da vida, de naturalização das violações de direitos humanos, de negação da ciência e de uma ampla campanha de difamação da educação superior ganham eco de forma naturalizada. Nessa onda conservadora presente na sociedade, a defesa dos princípios éticos da profissão nunca foi tão necessária, e a realização da parceria com a universidade se coloca também como uma forma de enfrentamento coletivo a essa conjuntura permeada de contradições.

É nesse cenário de retrocessos da ofensiva ultraconservadora do capital aos direitos sociais que o Cress-RJ, Seccional Norte Fluminense, realiza curso de extensão junto ao Gripes e à Coordenação do Serviço Social de um Hospital, com o intuito de qualificar a atuação de assistentes social, trabalhadoras da saúde, de forma mais específica, da rede hospitalar. O curso foi aberto as profissionais de vários municípios de abrangência da Seccional.

A realização da extensão foi construída considerando que um dos desafios colocados as profissionais é de formular projetos que materializem o trabalho a ser desenvolvido, principalmente quando o espaço ocupacional é permeado por um modelo de atenção com foco no cuidado biomédico. O curso trouxe diversas reflexões, a respeito do exercício profissional, de como vem ocorrendo à intervenção profissional e como essa intervenção vem respondendo às necessidades sociais dos usuários que procuram o setor do Serviço Social na rede hospitalar. Aspectos jurídico-legais foram destacados como fundamentais para o trabalho, tais como: a Lei n. 8.662, de 7 de junho de 1993 (BRASIL, 1993), que regulamenta a profissão, e o Código de Ética de 1993 (CFESS, 1993), que define as competências e os valores éticos norteadores do trabalho profissional, bem como os arcabouços teórico-metodológicos.

Atuando na centralidade de diferentes políticas públicas, Iasi (2018) aponta que o

[...] profissional do Serviço Social tem o risco potencializado de ser o administrador da gestão da precarização do acesso a serviços. Certamente as condições objetivas e subjetivas decorrentes da redução do Estado na função de garantia de direitos, de capital, impõem [...] ações e papeis profissionais cada vez mais multifacetados e voltados à eficiência técnica e à resolução imediata das problemáticas sociais" (SIMIONATTO, 2009, p. 101), ecoando uma ação esvaziada da competência crítica e, em alguns casos, burocratizada e na contramão do projeto profissional do Serviço Social brasileiro.

A realização do curso de extensão em parceria com o Gripes foi importante espaço para que as assistentes sociais pudessem, a partir do trabalho profissional, refletir sobre as demandas postas pela instituição, sobre as trazidas pelos usuários, sobre a precarização dos serviços de saúde e sobre as respostas que vem sendo fornecidas. Destacaram ainda o trabalho coletivo realizado pela comissão de Serviço Social da Fundação no início da implantação dos plantões do Serviço Social e da necessidade de retorno da organização coletiva.

A outra experiência com o Gripes, no ano de 2019, ocorreu a partir da demanda da Comissão de Orientação e Fiscalização da Seccional (Cofi), pois, dentre as funções precípuas do Cress, está o trabalho de fiscalização do exercício profissional. Destacamos aqui que o trabalho da Cofi é pautado na Política Nacional de Fiscalização (PNF, 2019), do conjunto Cfess/Cress, na perspectiva da defesa da profissão e da qualidade dos serviços prestados aos/às usuários/as dos serviços sociais. Na PNF, o sentido da fiscalização atua com três dimensões, organicamente vinculadas: "[...] afirmativa de princípios e compromissos conquistados; político-pedagógica; normativa e disciplinadora" (CFESS/CRESS - PNF, 2019). 
Neste sentido, a articulação com o Gripes ocorreu, pois a Secretaria de Saúde de Campos dos Goytacazes, no ano de 2018, distribuiu as assistentes sociais que atuavam junto à Coordenação do Serviço Social para outros setores de Secretaria, pois estariam acabando com o setor de coordenação e de atuação no setor de processos. As profissionais procuraram a Cofi e, a partir da escuta, foi deliberada uma visita a todos os setores da prefeitura para onde as profissionais foram transferidas, bem como uma defesa da Seccional sobre o papel da coordenação do Serviço Social. A Cofi inicia as visitas, e a falta de condições de trabalho foi identificada pela agente fiscal, mas também a realização de um trabalho burocratizado.

Certamente as condições de trabalho da assistente social, na atualidade, correspondem às condições de outros trabalhadores, pois o momento histórico é marcado por novas formas de opressão pelo trabalho. Para pensar o trabalho profissional para o Serviço Social, é necessário considerar que, como classe trabalhadora, as mudanças no âmbito do sistema capitalista, influenciam nos diferentes espaços ocupacionais, e o projeto profissional da categoria aponta a necessidade de qualificação para lidar com competência, com as demandas postas a assistente social. Neste sentido, Iamamoto destaca os significados da qualificação profissional, visto que:

\begin{abstract}
Qualificar-se no sentido da competência profissional significa, pois, compreender que nas relações sociais derivadas da divisão de trabalho capitalista, a burocracia cinde os interesses particulares do interesse geral, na relação entre o público e o privado, e reforça a inversão na forma de tratar os homens e as coisas 'de modo invertido, ou seja, não como são na realidade, mas de acordo com sua imagem no mundo da burocracia' (IAMAMOTO, 2009, p. 355).
\end{abstract}

Após conclusão das visitas da Cofi e, diante da necessidade de qualificação das profissionais, a Seccional Norte Fluminense procurou a Secretaria de Saúde apontando a necessidade do coordenador como necessário à articulação das assistentes sociais e também da necessidade da qualificação profissional. A coordenação foi recomposta em 2019 e chamada, junto ao Gripes e a Cofi, para construção do curso sobre o trabalho profissional cujo conteúdo envolveu a reforma sanitária, os arcabouços legais que direcionam o projeto ético político da categoria, a importância da sistematização do trabalho e normativas do Cfess/Cress que versam sobre a atuação profissional.

A realização do curso foi bastante elogiada pelas profissionais que participaram, sendo evidenciada a necessidade da atuação mais coletiva da categoria, visando dar maior visibilidade às respostas que as profissionais vêm fornecendo àqueles que demandam serviços e também ao encaminhamento coletivo dos serviços não prestados à população, considerando toda conjuntura de restrição e de violação de direitos já apontada neste capítulo, pois a defesa do direitos da classe trabalhadora se constitui uma escolha clara no projeto profissional das assistentes sociais.

A experiência aqui descrita de parceria com a universidade, a partir do Gripes, evidencia que a qualidade do trabalho realizado pelas assistentes sociais que atuam na área de saúde envolve a dimensão técnico-operativa da profissão, cujos sistemas eletrônicos não se devem sobrepor ao trabalho profissional, e também à dimensão teórico-metodológica, pois são postos limites ao exercício para atuar com as múltiplas expressões da questão social, fruto da "contradição capital x trabalho", (IAMAMOTO, 1988). Nesse limite da contrição, as assistentes sociais atuam sempre no "fogo cruzado", conforme descreve Maurilio Matos: 
Assim, não há dúvidas de que os assistentes sociais atuam sob fogo cruzado. Impossível não saber, na prática das configurações que o capitalismo inscreve na vida das pessoas. O 'fogo cruzado' aqui não é trazido apenas como termo popular, mas como expressão refere-se a existência de dois fogos, vindo de direções contrárias. Não é possível ficar no meio. Iamamoto (1995) já nos disse que é impossível ser mediador de interesses, tanto do seu empregador como dos interesses dos usuários. Necessariamente o profissional escolhe um desses polos e por meio do seu exercício o fortalece (MATOS, 2013, p. 145).

A experiência de parceria realizada junto à universidade ocorre num momento de sucateamento, não somente dos serviços públicos, com impactos diretos na atuação profissional, mas também da universidade pública, com drásticas reduções de alocação de verbas, concomitantemente com fortes impactos no trabalho realizado pela assistente social que exerce sua profissão na função de docente.

Essa reflexão sobre como a extensão e a pesquisa universitária corrobora o aprimoramento do trabalho profissional também demonstrou o compromisso incessante e coletivo da gestão da Seccional com a defesa do projeto ético-político e da profissão, no território de jurisdição, evidenciando a importância da universidade e o papel social proporcionado pela extensão, entendida como um processo interdisciplinar e educativo no aprimoramento profissional da assistente social.

\section{Considerações finais}

O capítulo objetivou abordar os atuais desafios da pesquisa e da extensão universitárias, considerando a conjuntura nacional marcada por ataques à ciência, especialmente às Ciências Humanas e Sociais. Posteriormente foram descritas análises referentes à experiência construída entre o Gripes, o Cress, 7. Região, Seccional Norte Fluminense (gestão 2017-2020) e a coordenação do Serviço Social de um hospital de referência na região, no período de 2017 a 2019, por meio do desenvolvimento de um projeto de pesquisa e extensão direcionado às assistentes sociais da área da saúde.

De forma geral, ao longo do capítulo, reconheceu-se que os atuais ataques à ciência se vinculam a um processo histórico construído por meio da chamada pós-verdade, que tem, por centralidade, o negacionismo científico e que, na particularidade brasileira, é processada em uma conjuntura marcada pelo radicalismo neoliberal que se articula com o avanço do conservadorismo, com o ataque a direitos trabalhistas, com o desfinanciamento de políticas sociais, com críticas às universidades públicas e cortes em seu orçamento, sucateando o ensino superior público, congelando pesquisas, reduzindo bolsas de estudos e ameaçando a continuidade de serviços e de laboratórios.

Nesse cenário, tem sido urgente a construção de estratégias coletivas que objetivem o desocultamento das contradições da sociedade do capital e a mobilização de recursos para o seu enfrentamento. Nessa direção, o capítulo descreveu análises construídas pela coordenação do Gripes, do Cress, Seccional Norte Fluminense (gestão 2017-2020) e de um hospital de referência na região, relativas a um projeto de pesquisa e extensão direcionado a assistentes sociais e a estagiárias do Serviço Social. 
De forma geral, reconheceu-se a importância do pensamento e da prática social coletiva como estratégias essenciais para desocultar as contradições presentes na realidade social. Além disso, compreendeu-se que a experiência construída contribuiu não apenas na direção de superação de técnicas pontuais de investigação, mas também para a qualificação continuada de assistentes sociais, construídas sob o parâmetro da crítica, contribuindo para a suspenção temporária de seu cotidiano de trabalho, oxigenando as percepções que têm da instituição, das demandas, das possibilidades e dos limites do trabalho.

\section{Referências}

BRASIL. Lei n. 8.662, de 7 de junho de 1993. Lei de Regulamentação do Serviço Social. Brasília: Presidência da República, [1993]. Disponível em: http://www.planalto.gov.br/ccivil_03/leis/18662.htm. Acesso em: 12 jun. 2021.

CONSELHO FEDERAL DE SERVIÇO SOCIAL (Cfess). Código de ética do assistente social: Lei 8.662/93 de regulamentação da profissão. 10. ed. rev. e atual. Brasília: Conselho Federal de Serviço Social, 2012.

CONSELHO FEDERAL DE SERVIÇO SOCIAL (Cfess). Política Nacional de Educação Permanente

CONSELHO FEDERAL DE SERVIÇO SOCIAL (Cfess). Política Nacional de

Fiscalização. Instrumentos para a fiscalização do exercício profissional do/a Assistente Social. Edição revista e atualizada. Brasília: CFESS, 2019. Disponível em:

http://www.cfess.org.br/arquivos/CFESS-PNF2019-Revisada.pdf. Acesso em: 12 maio 2021.

CONSELHO FEDERAL DE SERVIÇO SOCIAL (Cfess). Parâmetros para atuação de assistentes sociais na saúde. Grupo de trabalho Serviço Social na saúde. Brasília, CEFESS, nov. 2009.

GIOLO, J.; ROBERTO, L.; SGUISSARDI, V. Future-se: ataque à autonomia das instituições federais de educação superior e sua sujeição ao mercado. São Carlos, SP: Diagrama, 2020. Disponivel em: https://nupe.blumenau.ufsc.br/files/2020/09/future-se-ebook.pdf. Acesso em: 30 maio 2020.

IAMAMOTO, M. V. Renovação e conservadorismo no Serviço Social: ensaios críticos. 6. ed. São Paulo: Cortez, 2002.

IAMAMOTO, M. V. O Serviço Social na contemporaneidade: trabalho e formação profissional. São Paulo: Cortez, 1995.

IAMAMOTO, M. V. Serviço social em tempo de capital fetiche: capitalismo financeiro, trabalho e Questão social. 4. ed. São Paulo: Cortez, 2009. 
IASI, M. L. Cinco teses sobre a formação social brasileira (notas de estudo guiadas pelo pessimismo da razão e uma conclusão animada pelo otimismo da prática). Serviço Social $\&$ Sociedade, [s. l.], n. 136, p. 417-438, set. 2019. ISSN: 2317-6318. DOI: https://doi.org/10.1590/0101-6628.187. Disponível em: https://doi.org/10.1590/01016628.187. Acesso em: 3 jun. 2021.

MATTOS, M. C. de. Serviço social, ética e saúde: reflexões para exercício profissional. São Paulo: Cortez, 2013.

MELLO, T. Para os que virão. Notaterapia, [s. l.], 26 fev. 2018. Disponível em: https://notaterapia.com.br/2018/02/26/os-10-melhores-poemas-de-thiago-de-mello/. Acesso em: 30 maio 2021.

MORAES, C. A. S. O Serviço Social brasileiro na entrada do século XXI: formação, trabalho, pesquisa, dimensão investigativa e a particularidade da saúde. 318 f. Tese (Doutorado em Serviço Social) - Programa de Estudos Pós Graduados em Serviço Social, Pontifícia Universidade Católica de São Paulo, São Paulo, 2016.

PIVARO, G. F.; JUNIOR, G. G. O ataque organizado à ciência como forma de manipulação: do aquecimento global ao coronavírus. Caderno brasileiro de ensino de Física, v. 37, n. 3, p. 1074-1098, dez. 2020.

PRATES, J. C. A pesquisa e a extensão no processo de ensino-aprendizagem da graduação e pós-graduação em Serviço Social. Textos \& contextos, Porto Alegre, v. 16, n. 1, p. 1-08, jan./jul. 2017.

SCHUTZ, J. A.; FUCHS, C.; COSTA, C. O. Universidade, pesquisa e docência: reflexões críticas sobre os abusos do atual governo. Rev. tempos espaços educ., [s. l.], v. 13, n. 32, e-12530, p. 1 19, jan./dez. 2020,

SIMIONATTO, I. Expressões ideoculturais da crise capitalista na atualidade e sua influência teórico-prática. In: CONSELHO FEDERAL DE SERVIÇO SOCIAL (Cfess). Serviço social: direitos sociais e competências profissionais. Brasília: Cfess/Abepss, 2009. p. 87-106.

TAUCHEN, G.; FÁVERO, A. O princípio da indissociabilidade universitária: dificuldades e possibilidades de articulação. Linhas Críticas, Brasília, DF, v. 17, n. 33, p. 403-419, maio/ago. 2011. 